\title{
Influence of Curing Mode on the Surface Energy and Sorption/Solubility of Dental Self-Adhesive Resin Cements
}

\author{
Hyun-Jin Kim ${ }^{1}$, Rafat Bagheri ${ }^{2, *}$, Young Kyung Kim ${ }^{3}$, Jun Sik Son ${ }^{4}$ and Tae-Yub Kwon ${ }^{5, *}$ \\ 1 Department of Dental Science, Graduate School, Kyungpook National University, Daegu 41940, Korea; \\ khjin0815@knu.ac.kr \\ 2 Dental Materials Department and Biomaterials Research Centre, Shiraz University of Medical Sciences, \\ Shiraz 7183643111, Iran \\ 3 Department of Conservative Dentistry, School of Dentistry, Kyungpook National University, \\ Daegu 41940, Korea; wisekim@knu.ac.kr \\ 4 Korea Textile Development Institute, Daegu 41842, Korea; sonjk1@empas.com \\ 5 Department of Dental Biomaterials, School of Dentistry, Kyungpook National University, \\ Daegu 41940, Korea \\ * Correspondence: bagherir@unimelb.edu.au (R.B.); tykwon@knu.ac.kr (T.-Y.K.); \\ Tel.: +98-9171115876 (R.B.); +82-53-660-6891 (T.-Y.K.)
}

Academic Editor: Marco Salerno

Received: 4 December 2016; Accepted: 25 January 2017; Published: 4 February 2017

\begin{abstract}
This study investigated the influence of curing mode (dual- or self-cure) on the surface energy and sorption/solubility of four self-adhesive resin cements (SARCs) and one conventional resin cement. The degree of conversion (DC) and surface energy parameters including degree of hydrophilicity $(\mathrm{DH})$ were determined using Fourier transform infrared spectroscopy and contact angle measurements, respectively $(n=5)$. Sorption and solubility were assessed by mass gain or loss after storage in distilled water or lactic acid for 60 days $(n=5)$. A linear regression model was used to correlate between the results (\%DC vs. DH and \%DC/DH vs. sorption/solubility). For all materials, the dual-curing consistently produced significantly higher $\% \mathrm{DC}$ values than the self-curing $(p<0.05)$. Significant negative linear regressions were established between the \%DC and DH in both curing modes $(p<0.05)$. Overall, the SARCs showed higher sorption/solubility values, in particular when immersed in lactic acid, than the conventional resin cement. Linear regression revealed that \%DC and DH were negatively and positively correlated with the sorption/solubility values, respectively. Dual-curing of SARCs seems to lower the sorption and/or solubility in comparison with self-curing by increased \%DC and occasionally decreased hydrophilicity.
\end{abstract}

Keywords: polymerization; self-adhesive resin cement; solubility; sorption; surface energy

\section{Introduction}

Self-adhesive resin cements (SARCs) have been developed to reduce the multiple clinical steps required for application of the luting agents. These materials include acidic, hydrophilic methacrylate monomers, which simultaneously demineralize and infiltrate the tooth substrate, resulting in micromechanical retention and potentially additional chemical bonding $[1,2]$. The use of SARCs also reduces the occurrence of post-operative sensitivity [2].

In general, the SARCs are categorized as dual-cured resin cements, in which both chemical-activating and light-activating mechanisms are involved. The degree of conversion (DC) of dual-cured resin cements is generally lower when they are self-cured than when dual-cured, although the extent is related to the initiation system in each material [3]. In particular, acidic monomers 
incorporated in the SARCs may lower the DC even in their dual-cure mode because they may chemically interact with the amine initiator in the materials [3]. Thus, some commercial SARCs include proprietary activator/initiator systems to overcome this incompatibility [3,4]. Nonetheless, the acidic nature of an SARC has been raised as one factor hampering its effective polymerization, especially under chemical polymerization [5].

In the oral environment, the sensitivity of resin cement to moisture increases, raising the possibility of deboning and dissolution of the material at the marginal gap, consequently resulting in weakening and fracture of the indirect restoration [1]. An increased sorption/solubility may present early hydrolytic degradation, which reduces the lifetime of indirect restorations [6]. Conventional resin cements are based on crosslinking monomers such as bisphenol A diglycidyl methacrylate (Bis-GMA), triethylene glycol dimethacrylate (TEGDMA), and urethane dimethacrylate (UDMA) are basically hydrophobic [7]. SARCs are more hydrophilic than conventional resin cements due to the incorporation of acidic monomers in specific concentrations [1,7], suggesting that such resin cements are more susceptible to water sorption and solubility [8].

Commercial SARCs, which vary greatly in their composition, have a wide range of surface energy characteristics including surface hydrophilicity/hydrophobicity [7], thereby resulting in different sorption/solubility one another [8]. In addition, the curing protocol of SARCs may affect the surface energy, when considering possible differences in the polymer network and residual monomers [9], thus also potentially affecting the degradation of the materials. However, there are few studies regarding the influence of SARC curing methods on the surface energy characteristics and, as a result, sorption/solubility.

Therefore, the purpose of this in vitro study was to investigate the influence of two curing modes (either dual- or self-cure) on the surface energy and sorption/solubility of four SARCs (RelyX U200, RXU; Maxcem Elite, MCE; BisCem, BC; and Multilink Speed, MLS) and one conventional resin cement (Duo-Link, DL) (as the control). Their codes, brand names, manufacturers, and main compositions are shown in Table 1. The DCs and surface energy parameters of each resin cement polymerized in either dual- or self-cure mode were calculated. The sorption and solubility of five resin cements were investigated after immersing them in either distilled water or lactic acid for 60 days. The null hypotheses tested were that the different curing modes do not affect (1) the surface energy parameters nor (2) the sorption/solubility values of the materials tested.

Table 1. Materials used in the present study.

\begin{tabular}{|c|c|c|c|c|}
\hline Code & Brand Name & Manufacturer & Composition * (Batch Number) & Filler Loading/Average Particle Size * \\
\hline RXU & RelyX U200 & $\begin{array}{l}\text { 3M ESPE, Seefeld, } \\
\text { Germany }\end{array}$ & $\begin{array}{l}\text { Base: Mono-, di-, and tri-glycerol esters of } \\
\text { phosphoric acid dimethacrylate, TEGDMA, } \\
\text { glass, silica, sodium persulfate, tert-butyl } \\
\text { peroxy-3,5,5-trimethylhexanoate; Catalyst: } \\
\text { substituted dimethacrylate, 1,12-dodecane } \\
\text { dimethacrylate, glass, silica, calcium hydroxide, } \\
\text { calcium salt of 1-benzyl-5-phenyl-barbic-acid, } \\
\text { sodium } p \text {-toluenesulfinate (574751) }\end{array}$ & $43 \mathrm{vol} \% / 12.5 \mu \mathrm{m}$ \\
\hline MCE & Maxcem Elite & $\begin{array}{l}\text { Kerr Corp., Orange, } \\
\text { CA, USA }\end{array}$ & $\begin{array}{l}\text { GPDM, TEGDMA, fillers, activators, stabilizers, } \\
\text { HEMA, cumene hydroperoxide, titanium } \\
\text { dioxide, pigments (5427018) }\end{array}$ & $69 \mathrm{wt} \%$ \\
\hline $\mathrm{BC}$ & BisCem & $\begin{array}{l}\text { Bisco Inc., } \\
\text { Schaumberg, IL, } \\
\text { USA }\end{array}$ & $\begin{array}{l}\text { Di-HEMA phosphate, Tetra-EGDMA, } \\
\text { glass (1500001067) }\end{array}$ & $\begin{array}{c}\text { Base: } 36 \text { vol \% (60 wt \%); Catalyst: } \\
40 \text { vol \% (62 wt \%)/Base: } 1.0 \mu \mathrm{m} ; \\
\text { Catalyst } 3.5 \mu \mathrm{m}\end{array}$ \\
\hline DL & Duo-Link & $\begin{array}{l}\text { Bisco Inc., } \\
\text { Schaumberg, IL, } \\
\text { USA }\end{array}$ & $\begin{array}{l}\text { Base: Bis-GMA, TEGDMA, UDMA, glass filler; } \\
\text { Catalyst: Bis-GMA, TEGDMA, glass filler } \\
(1500003655)\end{array}$ & $38 \mathrm{vol} \%(60 \mathrm{wt} \%) /<1.0 \mu \mathrm{m}$ \\
\hline
\end{tabular}

* Manufacturer supplied. Abbreviation of monomers in alphabetical order: Bis-GMA, bisphenol A diglycidyl methacrylate; Di-HEMA phosphate, di-2-hydroxyethyl methacryl hydrogenphosphate; GPDM, glycerol phosphate dimethacrylate; HEMA, 2-hydroxyethyl methacrylate; PEGDMA, polyethylene glycol dimethacrylate; TEGDMA, triethylene glycol dimethacrylate; Tetra-EGDMA, tetraethylene glycol dimethacrylate; UDMA, urethane dimethacrylate. 


\section{Results}

\subsection{Degree of Conversions (DC)}

Figure 1 represents the \%DC of the five resin cements, which underwent dual-curing with light irradiation or self-curing without light irradiation. For all the resin cements tested, the dual-cure mode consistently produced significantly higher \%DC values than the self-cure mode $(p<0.05)$. The conventional resin cements DL exhibited the highest \%DC values in both curing modes $(p<0.05)$. $\mathrm{BC}$ and MCE showed significantly lower \%DC values than the other materials, regardless of the curing mode applied $(p<0.05)$, with no statistical differences from each other $(p>0.05)$.

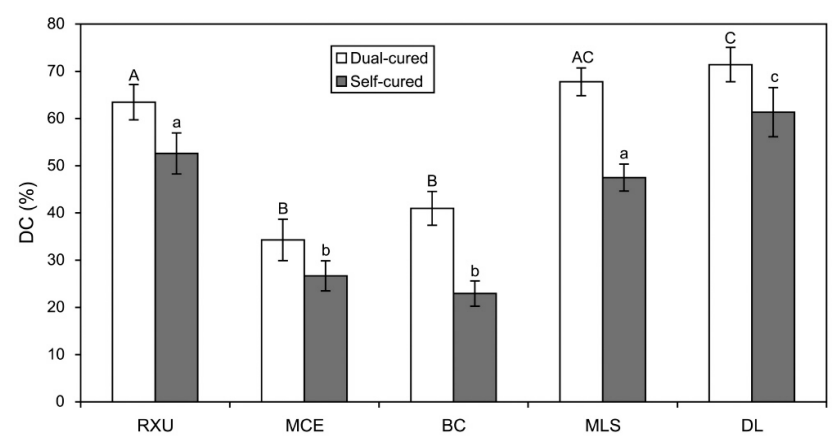

Figure 1. Degree of conversion (DC) of the resin cements polymerized in either dual- or self-cure mode $(n=5)$. The vertical bars indicate standard deviations. Upper- and lower-case letters indicate statistically similar means within the dual-cured and self-cured specimens, respectively $(p>0.05)$. For all materials, there were significant differences in the value between the two curing modes $(p<0.05)$.

\subsection{Surface Energy Parameters}

When the surface roughness of the resin cements was checked prior to the CA measurements, the mean $R_{\mathrm{a}}$ values ranged from 0.03 to $0.09 \mu \mathrm{m}$ (data not shown). The surface energy parameters of the materials tested are shown in Table 2 and Figure 2. For DL, there was no significant difference in each surface energy component between the two curing modes $(p>0.05)$. For the SARCs, on the other hand, significant differences in each component between the curing modes were found $(p<0.05)$, with the exception of $\gamma_{\mathrm{s}}{ }^{-}$values in MCE and MLS $(p>0.05)$. All the resin cements tested consistently showed large $\gamma_{\mathrm{s}}{ }^{\mathrm{LW}}$ and small $\gamma_{\mathrm{s}}{ }^{\mathrm{AB}}$ values, $\gamma_{\mathrm{s}}{ }^{-}$values being consistently greater than $\gamma_{\mathrm{s}}{ }^{+}$values. As shown in Figure 2, all the resin cements showed hydrophobic characteristics (negative $\Delta G_{\mathrm{sws}}$ ), with the exception of self-cured BC (positive $\Delta G_{\mathrm{Sws}}$ ). MCE, MLS, and DL did not show significant differences in the value between the two curing modes $(p>0.05)$, whereas self-cured RXU and BC were significantly more hydrophilic than dual-cured ones $(p=0.008)$.

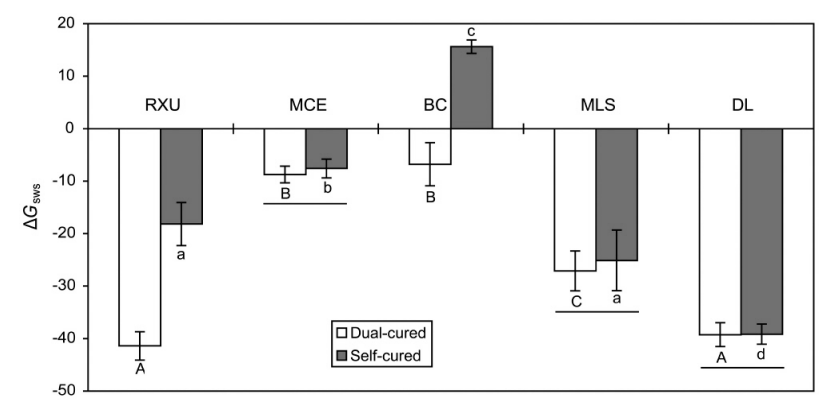

Figure 2. Degree of hydrophilicity (expressed as $\Delta G_{\mathrm{sws}}$ ) of the resin cements tested $(n=5)$. The same upper- and lower-case letters indicate statistically similar means within the dual- and self-cured specimens, respectively $(p>0.05)$. The horizontal bars connect statistically similar means between the two curing modes within each material $(p>0.05)$. 
Table 2. Mean values (standard deviations) of surface energy parameters $\left(\mathrm{mJ} / \mathrm{m}^{2}\right)$ of the resin cements tested $(n=5)$.

\begin{tabular}{ccccccc}
\hline \multirow{2}{*}{ Resin Cement } & Curing Mode & $\gamma_{\mathrm{s}}$ & $\gamma_{\mathrm{s}}{ }^{\mathrm{LW}}$ & $\gamma_{\mathrm{s}}{ }^{+}$ & $\gamma_{\mathrm{s}}{ }^{-}$ & $\gamma_{\mathrm{s}}^{\mathrm{AB}}$ \\
\hline \multirow{2}{*}{ RXU } & Dual-cured & $44.08(0.33)^{\mathrm{A}}$ & $43.58(0.38)^{\mathrm{A}}$ & $0.01(0.002)^{\mathrm{A}}$ & $11.20(1.01)^{\mathrm{A}}$ & $0.50(0.09)^{\mathrm{A}}$ \\
& Self-cured & $56.86(0.84)^{\mathrm{a}}$ & $49.01(0.45)^{\mathrm{a}}$ & $0.73(0.06)^{\mathrm{a}}$ & $21.35(2.47)^{\mathrm{ab}}$ & $7.85(0.50)^{\mathrm{a}}$ \\
\hline \multirow{2}{*}{ MCE } & Dual-cured & $37.90(1.52)^{\mathrm{B}}$ & $35.90(0.97)^{\mathrm{B}}$ & $0.05(0.03)^{\mathrm{B}}$ & $\underline{22.86(0.94)^{\mathrm{B}}}$ & $1.99(0.75)^{\mathrm{BC}}$ \\
& Self-cured & $52.03(0.74)^{\mathrm{b}}$ & $39.46(0.93)^{\mathrm{b}}$ & $1.66(0.35)^{\mathrm{b}}$ & $\underline{23.96(0.94)^{\mathrm{a}}}$ & $12.57(1.49)^{\mathrm{b}}$ \\
\hline \multirow{2}{*}{$\mathrm{BC}$} & Dual-cured & $42.98(1.03)^{\mathrm{A}}$ & $40.91(1.08)^{\mathrm{C}}$ & $0.04(0.02)^{\mathrm{B}}$ & $25.12(2.30)^{\mathrm{B}}$ & $2.08(0.43)^{\mathrm{BC}}$ \\
& Self-cured & $52.13(2.06)^{\mathrm{b}}$ & $33.75(1.38)^{\mathrm{C}}$ & $2.14(0.61)^{\mathrm{b}}$ & $39.98(1.65)^{\mathrm{C}}$ & $18.38(2.97)^{\mathrm{C}}$ \\
\hline \multirow{2}{*}{ MLS } & Dual-cured & $43.57(0.61)^{\mathrm{A}}$ & $41.78(0.36)^{\mathrm{C}}$ & $0.05(0.01)^{\mathrm{B}}$ & $\underline{15.87(1.54)^{\mathrm{C}}}$ & $1.79(0.27)^{\mathrm{B}}$ \\
& Self-cured & $48.22(1.14)^{\mathrm{C}}$ & $43.84(0.83)^{\mathrm{d}}$ & $0.29(0.02)^{\mathrm{C}}$ & $\underline{16.75(2.83)^{\mathrm{b}}}$ & $4.39(0.37)^{\mathrm{d}}$ \\
\hline \multirow{2}{*}{ DL } & Dual-cured & $\underline{46.27(1.11)^{\mathrm{C}}}$ & $43.50(1.14)^{\mathrm{A}}$ & $0.17(0.04)^{\mathrm{C}}$ & $\underline{11.12(1.01)^{\mathrm{A}}}$ & $\frac{2.77(0.28)^{\mathrm{C}}}{2.46(1.15)^{\mathrm{e}}}$ \\
\hline & Self-cured & $\underline{46.24(1.86)^{\mathrm{C}}}$ & $\underline{\underline{43.78(0.74)^{\mathrm{d}}}}$ & $\underline{\underline{0.16(0.14)^{\mathrm{C}}}}$ & $\underline{11.32(0.84)^{\mathrm{d}}}$ & $\underline{\underline{1.46}}$
\end{tabular}

$\gamma_{\mathrm{s}}$, total surface energy; $\gamma_{\mathrm{s}}{ }^{\mathrm{LW}}$, Lifshitz-van der Waals component; $\gamma_{\mathrm{s}}{ }^{+}$, acid component; $\gamma_{\mathrm{s}}{ }^{-}$, base component; $\gamma_{\mathrm{s}}{ }^{\mathrm{AB}}$, acid/base component. Within a column, the same superscripted upper- and lower-case letters indicate statistically similar means within the dual- and self-cured specimens, respectively $(p>0.05)$. Within a column, underlining indicates statistically similar means between the two curing modes within each material $(p>0.05)$.

Figure 3 shows the graphs of linear regression of $\Delta G_{\text {sws }}$ as a function of $\% \mathrm{DC}$ in the two curing modes. For both modes, significant negative linear regressions were established between the two parameters (dual-cured: $\mathrm{R}^{2}=0.815, p=0.036$; self-cured: $\mathrm{R}^{2}=0.836 ; p=0.030$ ).
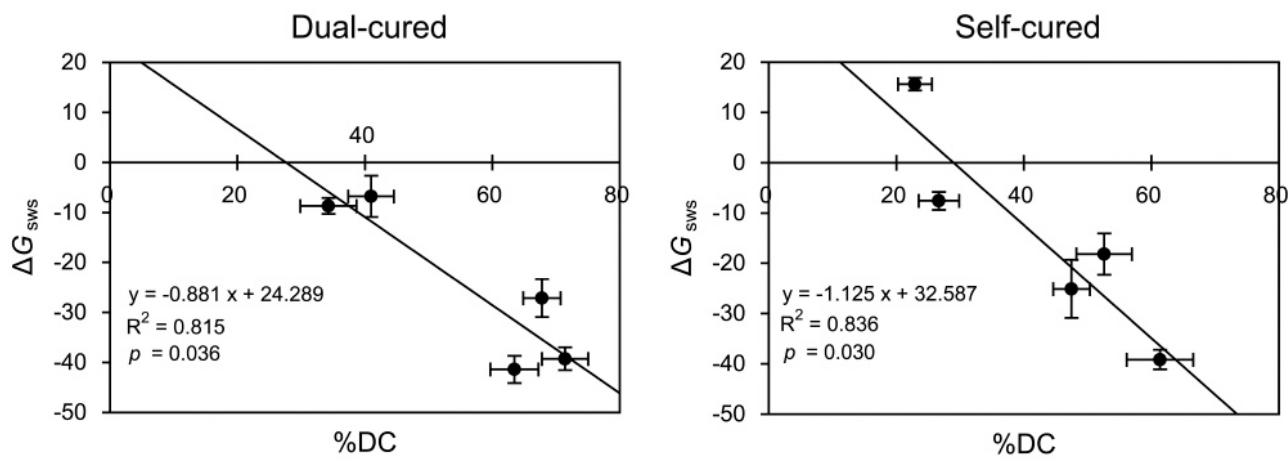

Figure 3. Graphs of linear regression of degree of hydrophilicity $\left(\Delta G_{\mathrm{sws}}\right)$ as a function of degree of conversion $(\% \mathrm{DC})$. The horizontal and vertical bars indicate standard deviations.

\subsection{Sorption and Solubility}

The sorption and solubility values of the resin cements immersed in either distilled water or lactic acid for 60 days are presented in Figures 4 and 5. Overall, the conventional resin cement DL exhibited the lowest sorption/solubility, with no statistical differences between the two curing modes $(p>0.05)$. On the contrary, the self-cured BC exhibited the highest sorption and solubility values. As for MCE and MLS, there were no significant differences in the sorption between the two curing modes $(p>0.05$, Figure 4), whereas the self-cure mode produced significantly higher solubility than the dual-cure mode $(p<0.05$, Figure 5). 

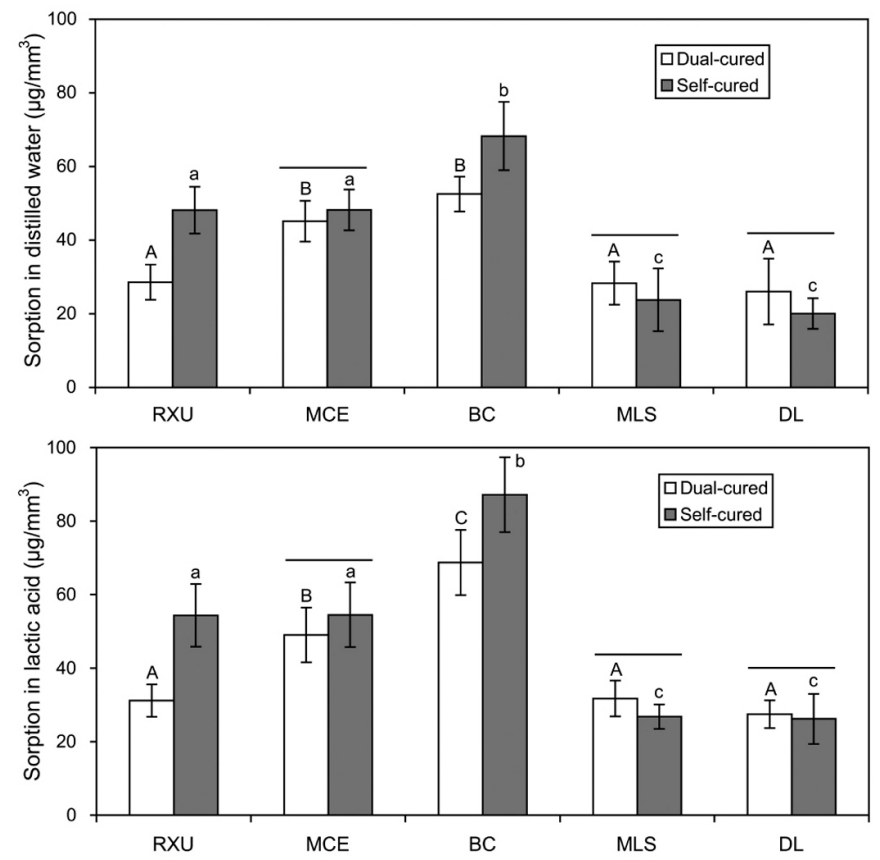

Figure 4. Sorption $\left(\mu \mathrm{g} / \mathrm{mm}^{3}\right)$ of the resin cements polymerized in either dual- or self-cure mode $(n=5)$. The vertical bars indicate standard deviations. The same upper- and lower-case letters indicate statistically similar means within the dual- and self-cured specimens, respectively $(p>0.05)$. The horizontal bars connect statistically similar means between the two curing modes within each material $(p>0.05)$.
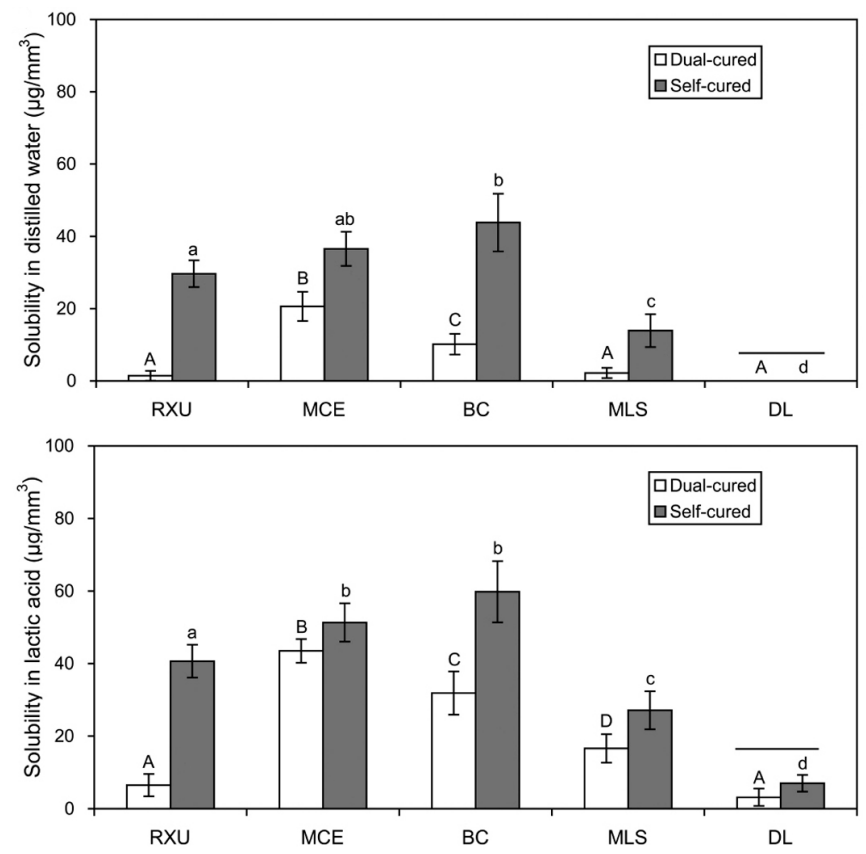

Figure 5. Solubility $\left(\mu \mathrm{g} / \mathrm{mm}^{3}\right)$ of the five resin cements polymerized in either dual- or self-cure mode $(n=5)$. The vertical bars indicate standard deviations. The same upper- and lower-case letters indicate statistically similar means within the dual- and self-cured specimens, respectively $(p>0.05)$. The horizontal bars connect statistically similar means between the two curing modes within each material $(p>0.05)$. 


\subsection{Linear Regressions}

Figures 6 and 7 show the graphs of linear regression of sorption/solubility as a function of $\% \mathrm{DC} / \Delta G_{\mathrm{sws}}$. For all cases, negative $(\% \mathrm{DC})$ or positive $\left(\Delta G_{\mathrm{sws}}\right)$ linear regressions were established between the $\% D C / \Delta G_{\text {sws }}$ and the sorption/solubility values. The $\Delta G_{\text {sws }}$ values consistently produced higher $\mathrm{R}^{2}$ values than the \%DC values for the sorption (Figure 6), whereas this tendency was less distinct for the solubility (Figure 7).
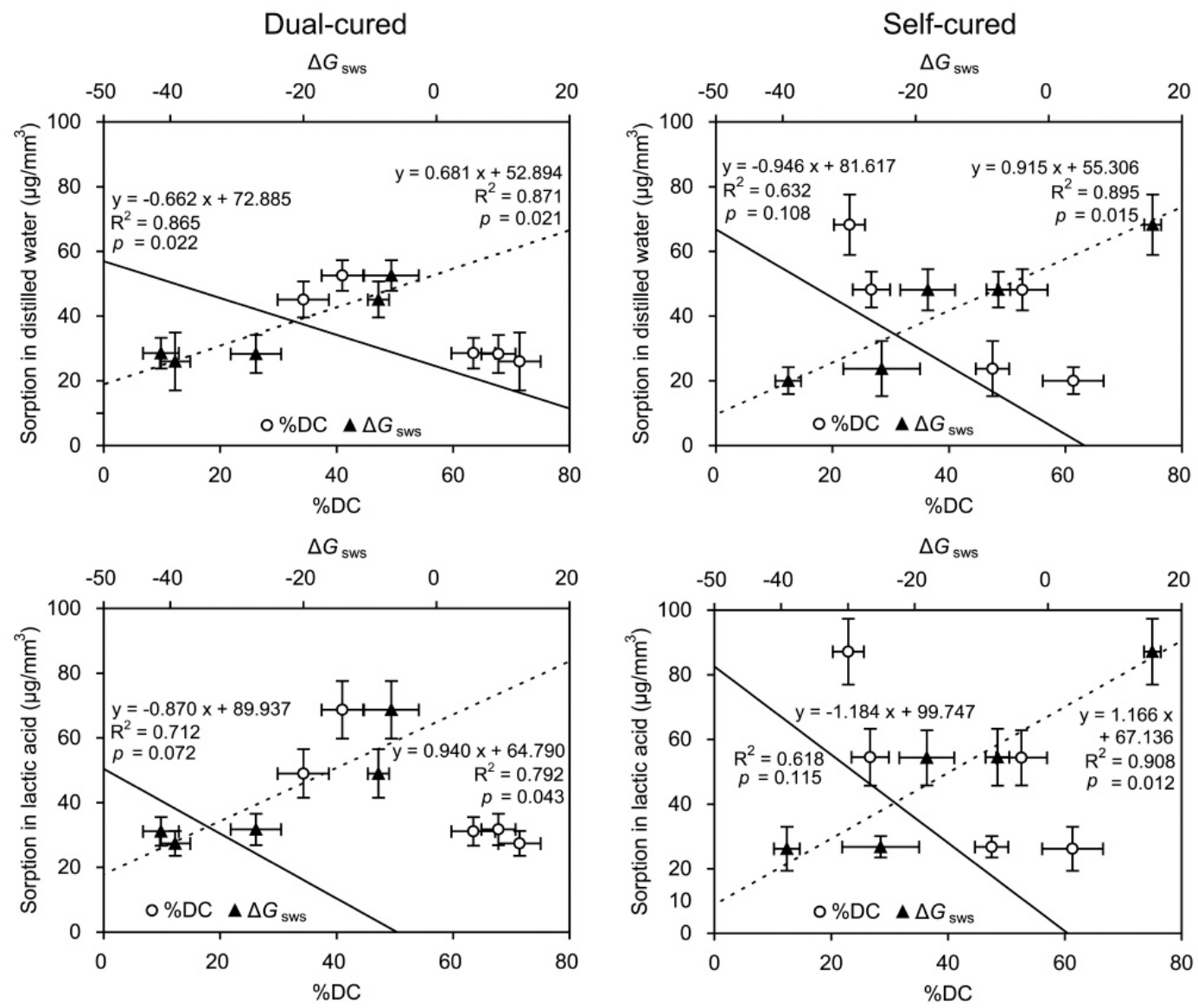

Figure 6. Graphs of linear regression of sorption $\left(\mu \mathrm{g} / \mathrm{mm}^{3}\right)$ as a function of degree of conversion (\%DC) and degree of hydrophilicity $\left(\Delta G_{\mathrm{sws}}\right)$. The horizontal and vertical bars indicate standard deviations.
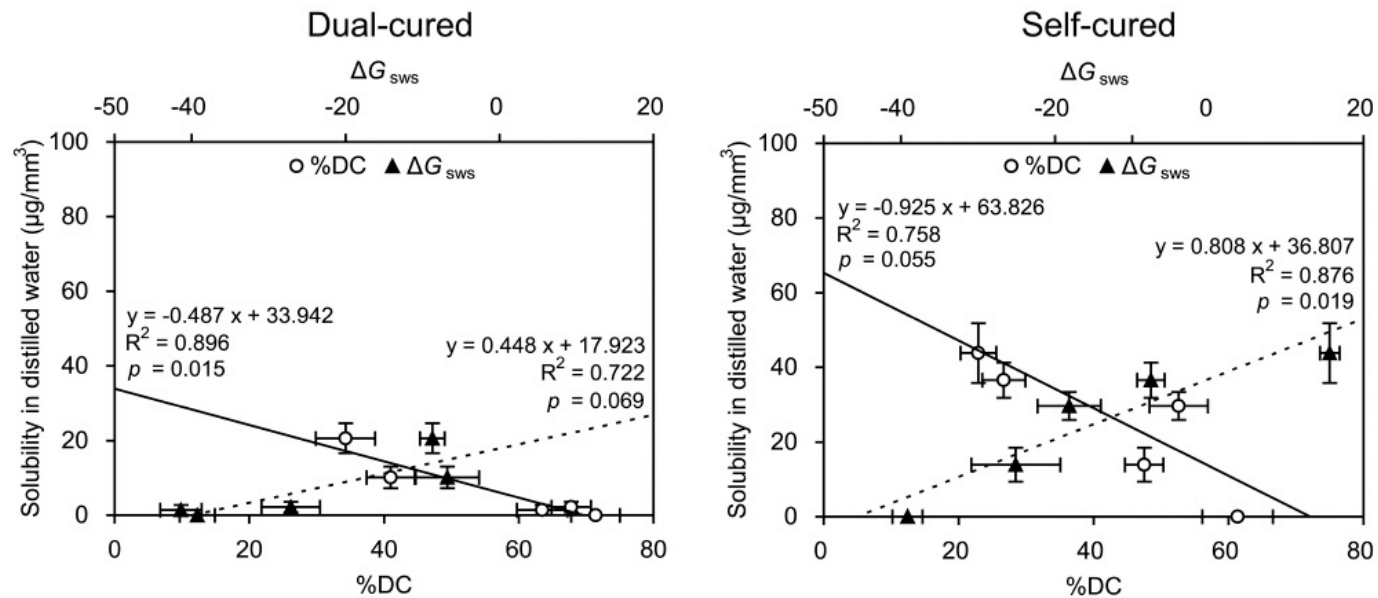

Figure 7. Cont. 

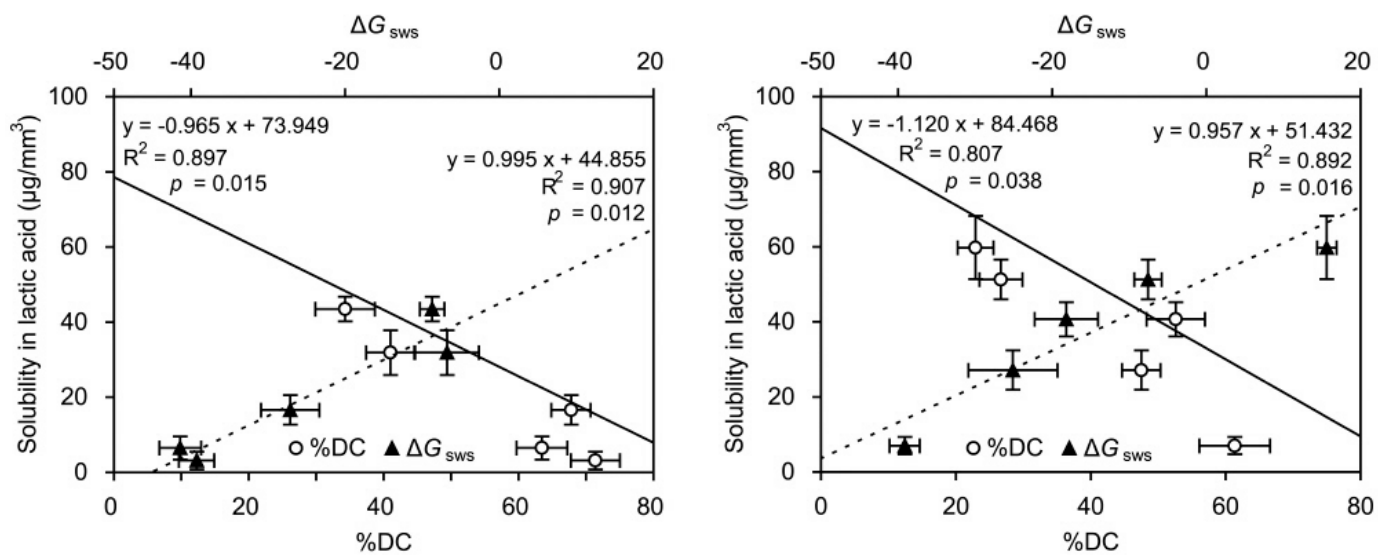

Figure 7. Graphs of linear regression of solubility $\left(\mu \mathrm{g} / \mathrm{mm}^{3}\right)$ as a function of degree of conversion $(\% \mathrm{DC})$ and degree of hydrophilicity $\left(\Delta \mathrm{G}_{\mathrm{sws}}\right)$. The horizontal and vertical bars indicate standard deviations.

\section{Discussion}

In the present study, four SARCs, containing various phosphoric ester monomers, and one conventional resin cement, were tested (Table 1). The hydrophobic crosslinking monomers Bis-GMA, TEGDMA, and UDMA in the resin cements also have polar hydrophilic sites (hydroxyl, ethylene oxide, and urethane groups, respectively), which can serve as water absorption sites [10,11], leading to swelling of the cured resin as well as increased hydrolysis susceptibility [12]. Moreover, the functional groups (e.g., phosphate and carboxyl groups) in acidic monomers, which are commonly incorporated into self-etching resin cements and SARCs, usually exhibit strong hydrophilic characteristics [12], potentially resulting in high sorption and solubility after polymerization [1].

The surface roughness of the resin cements was checked prior to measuring the CAs because changes in $R_{\mathrm{a}}$ above $0.1 \mu \mathrm{m}$ can influence the value, thereby altering the surface energy characteristics [13-15]. In this study, there were only small variations in $R_{\mathrm{a}}$ (below $0.1 \mu \mathrm{m}$ ) among the resin cement surfaces prepared against a Mylar polyester film.

In general, the surface energy parameters of resin-based materials are calculated from the CA values measured on polymerized surfaces because it is actually impossible to make an unpolymerized surface flat and smooth $[7,11,14,16]$. In this case, the basic assumption is that the surface energy parameters of uncured and cured resin materials would be similar since all groups and segments of the functional monomers are also present in the polymer, with the exception of the vinyl groups [14,16]. However, the findings of this study suggest the surface hydrophilicity of some SARCs (RXU and BC in this study) are significantly altered depending on the curing mode used (Figure 2). The conventional resin cement (DL) did not exhibit a significant difference in $\Delta G_{\text {sws }}$ between the two curing modes, notwithstanding a significant difference in \%DC (Figure 1). RXU and BC exhibited significantly lower $\Delta G_{\text {sws }}$ (more hydrophobic) in the dual-cure mode than in self-cure mode, likely due to significantly lowered strength of $\gamma_{\mathrm{s}}{ }^{-}$in the dual-cure mode (Table 2). On the contrary, MCE and MLS did not demonstrate significant differences in $\Delta G_{\mathrm{sws}}$ between the two curing modes. These findings imply that, in some cured SARCs, different arrangements of functional groups of the acidic monomers during polymerization (depending on the curing mode used) may result in differences in the surface energy characteristics between the two curing modes [9]. Since the influence of curing mode on surface energy parameters was found to be material-dependent, the first hypothesis has to be partially rejected.

Taking $\Delta G_{\mathrm{sws}}=0$ as the boundary between hydrophobicity and hydrophilicity [17], all the dual- or self-cured resin cements tested were found to present a mainly hydrophobic character with the exception of the self-cured BC (Figure 2). As seen in Figure 3, the DHs (expressed as $\Delta G_{\text {sws }}$ ) of the resin cements were strongly negatively correlated with the \%DCs in both curing modes. The high $\mathrm{R}^{2}$ (coefficient of determination) values suggest that $\Delta G_{\text {sws }}$ may serve as a surrogate measure of DC of 
the resin cement. However, further research is needed to determine how surface energy changes as polymerization progresses [18].

When resin-based composites are immersed in aqueous solutions, a solvent such as water can intermingle with the polymer matrix physically (plasticization) and chemically (hydrolysis and degradation) [1,19]. The solvent diffuses into the resin network and reduces the intermolecular interaction of the polymer chains (swelling), yielding an increase in weight (sorption) [1]. Meanwhile, solubility in a resin-based composite reflects the amount of released residual or leachable monomers as well as filler particles from its surface, resulting in loss of weight $[1,20]$. The release of uncured monomers also presents a potentially sensitizing and irritating factor for the oral tissues [21].

As seen in Figures 4 and 5, the sorption and solubility values of the resin cements polymerized in either dual- or self-cure mode were generally affected by the DC (Figure 1) and/or surface energy parameters (Table 2 and Figure 2). Therefore, the second hypothesis that the curing modes do not affect the sorption/solubility of the resin cements was rejected. In the Lewis acid-base interactions, the Lewis acid $\left(\gamma_{\mathrm{s}}{ }^{+}\right)$and the Lewis base $\left(\gamma_{\mathrm{s}}{ }^{-}\right)$components can be regarded as hydrogen bond donating and accepting, respectively $[7,14]$. All luting cements tested showed large $\gamma_{\mathrm{s}}{ }^{-}$values and very small $\gamma_{\mathrm{s}}{ }^{+}$ values (Table 2), indicating a predominantly hydrogen bond accepting character rather than donating character [14]. Water, as a solvent, can establish hydrogen bonds with the polar sites (in particular, hydrogen accepting sites) of polymer networks or even residual unreacted monomers, which are present in the polymer networks or trapped in voids and pores during polymerization, in the cured resin-based composite [1]. Furthermore, resin-based composites containing higher concentrations of acidic monomers having higher polarity can develop a higher level of hydrogen bonds with water, thereby increasing the liquid uptake [1,14].

Distilled water and lactic acid were chosen as storage media in this study. Artificial saliva may simulate the liquids that constantly interact with teeth and restorations in the mouth in a more clinically relevant manner. It has been shown that water and artificial saliva are generally comparable as storage media in terms of water sorption [22]. However, the continued adsorption of artificial saliva components may mask the actual solubility of the resin materials [22]. Lactic acid is one of the main acids produced by human dental plaque [20], which may accelerate surface degradation of resin-based composites $[23,24]$. In this study, the effect of lactic acid on the resin cements was generally more deleterious than that of distilled water in the degradation of the materials (Figures 4 and 5), in accordance with the results of previous studies $[1,20,25,26]$. A study by da Silva et al. [20] reported that the highest diffusion coefficient occurred when resin-based composites were immersed in lactic acid, indicating a faster diffusion of lactic acid inside the resins than distilled water. Lactic acid with the polar functional groups (hydroxyl $(-\mathrm{OH})$ and carboxyl $(-\mathrm{COOH})$ groups) may form more hydrogen bonds with resin cements, particularly with SARCs, as compared to water [1]. Such hydrogen bonding potential of the phosphoric ester monomers may also depend on their chemical structures [14].

In this study, BC exhibited the greatest sorption and solubility values among the four SARCs tested (Figures 4 and 5), which can partly be attributed to the presence of HEMA, together with acidic monomers, in its composition (Table 1). HEMA is a highly hydrophilic monomer used for enhanced adhesion promotion [12,14]. Nevertheless, HEMA will readily absorb water both in uncured and even cured states [12]. The conventional resin cement DL, not having any acidic monomers, showed only a low degree of sorption/solubility. Slight water sorption sometimes may be favorable in compensating resin polymerization shrinkage, thus relieving internal shrinkage stresses and potentially improving marginal seal [1].

The regression analysis results (Figures 6 and 7) clearly show that the slope of the prediction line of the sorption/solubility decreased and increased linearly with increasing $\% \mathrm{DC}$ and $\Delta G_{\mathrm{sws}}$, respectively. In general, the DC of a resin-based composite provides valid information about the durability and biological safety of the material because it affects the mechanical properties and degradation by water and/or oral acids [21,27]. As seen in Figure 6, the consistently steeper slope of the lines (higher $R^{2}$ values) suggests that the sorption characteristics of the resin cements could be better explained by 
the variations in the $\Delta G_{\mathrm{sws}}$ than by those in the \%DC among the materials. In regard to solubility, such predominant effects of $\Delta G_{\text {sws }}$ values were less distinct (Figure 7). MCE and MLS showed statistically similar sorption values in both immersion media (Figure 4), but significantly higher solubility values were found in the self-cure mode than in the dual-cured mode (Figure 5). The solubility behavior of a resin cement may instead be related to the elution of unreacted components, the amount of which is inversely proportional to the DC [1]. The findings of this study suggest that surface energy characteristics should be taken into account in the analysis of resin material degradation. Measuring CA might be regarded as a simple method for roughly estimating the sorption/solubility behavior of resin cements, together with DC.

Kim et al. [14] demonstrated that the shear bond strength of various luting cements to zirconia ceramic was positively correlated with the base components $\left(\gamma_{\mathrm{s}}{ }^{-}\right.$values $)$of the materials. The base components of a resin-based composite seem to govern the DH (Table 2 and Figure 2) [11]. In this study, MCE, MLS, and DL, with no significant differences in the $\gamma_{\mathrm{s}}{ }^{-}$value between the two curing modes, also showed no significant differences in $\Delta G_{\text {sws }}$ value. Kim et al. [11] reported that the more hydrophobic SARCs produced higher shear bond strengths to dentin than the more hydrophilic ones, indicating that large base components (high $\gamma_{\mathrm{s}}{ }^{-}$values) and, as a result, increased $\mathrm{DH}$, do not necessarily indicate enhanced bonding to a dental substrate. Such high DH of SARCs also is unfavorable in terms of sorption/solubility. Therefore, SARCs with optimal surface energy characteristics should be formulated to enhance the bonding behavior but decrease the sorption/solubility.

The findings of this study suggest that commercial SARCs may suffer a higher degradation than conventional resin cements in the oral environment, especially when the materials are partially polymerized by self-curing [28]. Therefore, dual-cured resin cements-including SARCs-should achieve their maximum DC and, if possible, high surface hydrophobicity to withstand such intraoral challenges [29]. Increased water sorption of a resin cement can degrade its mechanical properties by the plasticizing effect and also by dissolving and leaching out of unreacted monomers and filler particles $[9,19,29,30]$. Changes in bulk properties of the resin-based composite after immersion in a solution were not included in this study; further investigation is needed.

\section{Materials and Methods}

\subsection{Degree of Conversions (DC)}

The \%DC of the resin cements was determined using a Fourier transform infrared (FTIR) spectroscope (IRPrestige-21, Shimadzu Corp, Kyoto, Japan). A total of 50 ( $n=5$ per group) disc-shaped specimens $(6 \mathrm{~mm}$ in diameter and $1 \mathrm{~mm}$ in thickness) were prepared by polymerizing them in either dual- or self-cure mode, as follows. Cylindrical molds were placed on a Mylar polyester film over a glass slide (dual-cure) or metal plate (self-cure). Each resin cement was mixed in accordance with the corresponding instructions, filled into the mold, and then covered with another Mylar polyester film and then glass slide (dual-cure) or metal plate (self-cure) to form an assembly. In dual-cured groups, the materials were light-irradiated for $40 \mathrm{~s}$ by placing the light guide tip of a curing light (Bluephase ${ }^{\circledR} 20 \mathrm{i}$, Ivoclar Vivadent, Schaan, Liechtenstein) against the upper glass slide. The second side of the resin specimen was irradiated in the same way as the first side [31]. During the experiment, the output intensity $\left(2000 \mathrm{~mW} / \mathrm{cm}^{2}\right)$ was constantly monitored by a radiometer. The assembly was then transferred to a $37{ }^{\circ} \mathrm{C}$ oven. The specimen was removed from the mold 15 min after the start of irradiation [31], and the periphery was finished using silicon carbide paper to remove flash and irregularities. In the self-cured groups, the assembly was clamped together and transferred to the oven. The specimen was removed from the mold $60 \mathrm{~min}$ from the start of mixing [31], and the periphery was finished as described above. The dual- or self-cured specimens were stored in the oven until the start of testing ( $24 \mathrm{~h}$ after the start of irradiation (dual-cured) or mixing (self-cured)).

Each specimen was pressed against an attenuated total reflectance (ATR) prism (MIRacle, Pike Technologies Inc., Madison, WI, USA) in the FTIR instrument, and the absorbance spectrum was 
acquired by scanning 20 times over a 4000-700 $\mathrm{cm}^{-1}$ range with a resolution of $4 \mathrm{~cm}^{-1}$. Uncured material from each resin cement was also scanned, its spectrum being used as the uncured reference. The aliphatic $C=C$ peak at $1638 \mathrm{~cm}^{-1}$ was acquired, while either the aromatic $C=C$ peak at $1608 \mathrm{~cm}^{-1}$ (RXU, DL) or the N-H peak at $1537 \mathrm{~cm}^{-1}$ (MCE, BC, and MLS) were used as the internal calibration [32]. The $\%$ DC was determined by comparing the height of the peaks for the methacrylate vinyl group (aliphatic $\mathrm{C}=\mathrm{C}$ ) in the cured material against that in the uncured material, using the following equation: $\mathrm{DC}(\%)=\left(1-A_{\mathrm{c}} / A_{\mathrm{uc}}\right) \times 100$, where $A_{\mathrm{c}}$ and $A_{\mathrm{uc}}$ are the peaks for the cured and uncured materials, respectively.

\subsection{Surface Energy Parameters}

To investigate the surface energy of the resin cements, contact angles (CAs) of a liquid triplet were measured on the surfaces of the materials polymerized in either dual- or self-cure mode. CAs were determined on cured resin specimens, which had an outermost surface free of filler when cured in contact with a polyester film [16].

Prior to measuring the CAs, the surface roughness of the resin cements was checked because changes in roughness can alter the CA $[13,14]$. Five cured specimens for each group were prepared as described in Section 4.1. Average surface roughness $\left(R_{\mathrm{a}}\right)$ was measured using a profilometer (Surftest SV-400, Mitutoyo Corp., Kawasaki, Japan). The stylus speed, cutoff, and range used were $0.1 \mathrm{~mm} / \mathrm{s}$, $0.25 \mathrm{~mm}$, and $600 \mu \mathrm{m}$, respectively. Three measurements were performed on each resin specimen, and the average value was used.

For the CA measurements, five disc-shaped cured specimens for each group were prepared as described in Section 4.1. Water (W: $\left.\gamma: 72.8 ; \gamma^{\mathrm{LW}}: 21.8 ; \gamma^{+}: 25.5 ; \gamma^{-}: 25.5\right)$, glycerol (G: $\gamma: 64 ; \gamma^{\mathrm{LW}}: 34$; $\gamma^{+}: 3.92 ; \gamma^{-}: 57.4$ ), and methylene iodide (MI: $\gamma: 50.8 ; \gamma^{\mathrm{LW}}: 50.8$ ) were used as the test liquids (all in $\mathrm{mJ} \cdot \mathrm{m}^{-2}$ ) $[7,33]$. The CA of each of the three liquids was measured on the surfaces by the sessile drop method using a CA goniometer (OCA 15 plus, DataPhysics Instrument GmbH, Filderstadt, Germany). The CA measurements were carried out at $23 \pm 1{ }^{\circ} \mathrm{C}$ with relative humidity at 50\% $\pm 5 \%$ [34].

Surface energy components of a solid were calculated using the Young-Dupré equation combined with the Lifshitz-van der Waals/Lewis acid-base theory [7,14]: $\gamma_{1}(1+\cos \Theta)=2\left[\left(\gamma_{s}{ }^{L W} \gamma_{1}{ }^{L W}\right)^{1 / 2}+\right.$ $\left.\left(\gamma_{\mathrm{s}}^{+} \gamma_{1}{ }^{-}\right)^{1 / 2}+\left(\gamma_{\mathrm{s}}{ }^{-} \gamma_{1}{ }^{+}\right)^{1 / 2}\right]$, where $\Theta$ is the contact angle; $\gamma_{1}$ and $\gamma_{\mathrm{s}}$ are the surface tensions of the liquid (l) and solid (s) surfaces, respectively; and the superscripts LW, +, and - refer to the Lifshitz-van der Waals, acid, and base components, respectively. The total surface energy $\gamma_{\mathrm{s}}$ was derived by the equation [7,14]: $\gamma_{s}=\gamma_{s}{ }^{L W}+\gamma_{s}{ }^{A B}=\gamma_{s}{ }^{L W}+2\left(\gamma_{s}{ }^{+} \gamma_{s}{ }^{-}\right)^{1 / 2}$, where $\gamma_{s}{ }^{A B}$ is the acid/base component.

The degree of hydrophilicity $(\mathrm{DH})$ of the materials was further investigated using thermodynamic notation. The work of cohesion, $W_{c}$, is expressed by using the free energy, $G$, so that $\Delta G_{\mathrm{C}}=-2 \gamma=-W_{\mathrm{c}}[35]$. The DH of a material is related to the magnitude of $\Delta G_{\mathrm{sws}}=-2 \gamma_{\mathrm{sw}}$, where $\gamma_{\mathrm{sw}}=\gamma_{\mathrm{sw}}{ }^{\mathrm{LW}}+\gamma_{\mathrm{sw}}{ }^{\mathrm{AB}}$, in which $\mathrm{w}$ indicates water. The $\gamma_{\mathrm{sw}}{ }^{\mathrm{LW}}$ and the $\gamma_{\mathrm{sw}} \mathrm{AB}$ were calculated using the equations, respectively [17]: $\gamma_{\mathrm{sW}}{ }^{\mathrm{LW}}=\left[\left(\gamma_{\mathrm{s}}^{\mathrm{LW}}\right)^{1 / 2}-\left(\gamma_{\mathrm{W}}^{\mathrm{LW}}\right)^{1 / 2}\right]^{2}$ and $\gamma_{\mathrm{sw}}{ }^{\mathrm{AB}}=2\left[\left(\gamma_{\mathrm{s}}{ }^{+} \gamma_{\mathrm{s}}{ }^{-}\right)^{1 / 2}+\right.$ $\left.\left(\gamma_{\mathrm{w}}{ }^{+} \gamma_{\mathrm{w}}{ }^{-}\right)^{1 / 2}-\left(\gamma_{\mathrm{s}}{ }^{+} \gamma_{\mathrm{w}}{ }^{-}\right)^{1 / 2}-\left(\gamma_{\mathrm{w}}{ }^{+} \gamma_{\mathrm{s}}{ }^{-}\right)^{1 / 2}\right] . \Delta G_{\mathrm{sws}}=0$ was considered as the boundary between hydrophobicity and hydrophilicity [17]. When $\Delta G_{\mathrm{sws}}$ is positive, the surface of the material is hydrophilic (high DH); when $\Delta G_{\text {sws }}$ is negative, that of the material is hydrophobic (low DH) [17].

\subsection{Sorption and Solubility}

For the sorption/solubility test, 10 specimens were prepared for each group (five for immersion in distilled water and five in lactic acid) as described in Section 4.1 [25]. The specimens were stored in two desiccators (at $37^{\circ} \mathrm{C}$ for $22 \mathrm{~h}$ and then at $23^{\circ} \mathrm{C}$ for $2 \mathrm{~h}$ ) and repeatedly weighed after 24-h intervals using a balance (DVG214C, Ohaus Corp., Parsippany, NJ, USA) to an accuracy of $0.1 \mathrm{mg}$ until a constant mass $\left(m_{1}\right)$ was obtained [31]. After calculating the volume $\left(V\right.$, in $\left.\mathrm{mm}^{3}\right)$ of the specimens by measuring the dimensions using a digital caliper, the specimens were individually placed in lightproof glass vials containing either distilled water $(\mathrm{pH}=7)$ or $0.01 \mathrm{M}$ lactic acid $(\mathrm{pH}=4)$ maintained at $37^{\circ} \mathrm{C}[1,20]$. Fresh distilled water and lactic acid solutions were replaced daily to avoid variation 
in $\mathrm{pH}$ [1]. After 60 days, the specimens were removed from the immersion solutions and gently rinsed with water. Visible surface liquid was then removed by blotting with absorbent paper and waving the specimens in the air [31], and $m_{2}$ was recorded. The specimens were then placed in the desiccators again, and reweighed until a constant mass $\left(m_{3}\right)$ was obtained. Sorption $\left(S_{P}\right)$ and solubility $\left(S_{\mathrm{L}}\right)$ during the 60-day immersion, in $\mathrm{ug} / \mathrm{mm}^{3}$, were calculated using the following formulae $[1,20]$ : $S_{\mathrm{P}}=\left(m_{2}-m_{3}\right) / V ; S_{\mathrm{L}}=\left(m_{1}-m_{3}\right) / V$.

\subsection{Statistical Analysis}

For all data which did not satisfy the equal variance assumption (Leven's test), non-parametric statistical procedures were applied. The Kruskal-Wallis test was employed among resin cements within each curing mode, followed by the Mann-Whitney post hoc test, with adjustment of significance levels using the Benjamini and Hochberg method of a false discovery rate; between two curing modes within each resin cement, the Mann-Whitney test was used [36]. Linear regression analyses were performed to correlate (1) the \%DC with the $\mathrm{DH}$ and (2) the \%DC/DH with the sorption/solubility for each curing mode. The statistical analysis was performed using SPSS 17.0 for Windows (SPSS Inc., Chicago, IL, USA) at $\alpha=0.05$.

\section{Conclusions}

This in vitro study investigated the influence of two curing modes on the surface energy and sorption/solubility of four SARCs (RXU, MCE, BC, and MLS) and one conventional resin cement (DL) (as the control). Within the limitations of this study, the following findings were noted:

- For all the resin cements tested, the dual-cure mode consistently produced significantly higher $\%$ DC values than the self-cure mode.

- Dual-curing of the two SARCs (RXU and BC) resulted in greater surface hydrophobicity as compared with self-curing, whereas curing mode had no significant effect in the other two SARCS (MCE and MLS) or in the conventional resin cement (DL).

- Overall, the SARCs exhibited greater sorption/solubility values than the conventional resin cement (DL), especially when self-cured. The effect of lactic acid on the materials was generally more deleterious than that of distilled water.

Acknowledgments: This work was supported by the National Research Foundation of Korea (NRF) grant funded by the Korea government (MSIP) (2008-0062282).

Author Contributions: Hyun-Jin Kim, Young Kyung Kim, Jun Sik Son, and Tae-Yub Kwon conceived and designed the experiments; Hyun-Jin Kim and Young Kyung Kim performed the experiments; Rafat Bagheri and Tae-Yub Kwon analyzed the data; Young Kyung Kim and Jun Sik Son contributed reagents/materials/analysis tools; Hyun-Jin Kim, Rafat Bagheri, and Tae-Yub Kwon wrote the paper.

Conflicts of Interest: The authors declare no conflict of interest.

\section{References}

1. Marghalani, H.Y. Sorption and solubility characteristics of self-adhesive resin cements. Dent. Mater. 2012, 28, 187-198. [CrossRef] [PubMed]

2. Moraes, R.R.; Boscato, N.; Jardim, P.S.; Schneider, L.F. Dual and self-curing potential of self-adhesive resin cements as thin films. Oper. Dent. 2011, 36, 635-642. [CrossRef] [PubMed]

3. Vrochari, A.D.; Eliades, G.; Hellwig, E.; Wrbas, K.T. Curing efficiency of four self-etching, self-adhesive resin cements. Dent. Mater. 2009, 25, 1104-1108. [CrossRef] [PubMed]

4. Kim, Y.K.; Chun, J.N.; Kwon, P.C.; Kim, K.H.; Kwon, T.Y. Polymerization kinetics of dual-curing adhesive systems when used solely or in conjunction with chemically-cured resin cement. J. Adhes. Dent. 2013, 15, 453-459. [PubMed] 
5. Moosavi, H.; Hariri, I.; Sadr, A.; Thitthaweerat, S.; Tagami, J. Effects of curing mode and moisture on nanoindentation mechanical properties and bonding of a self-adhesive resin cement to pulp chamber floor. Dent. Mater. 2013, 29, 708-717. [CrossRef] [PubMed]

6. Aguiar, T.R.; André, C.B.; Ambrosano, G.M.B.; Giannini, M. The effect of light exposure on water sorption and solubility of self-adhesive resin cements. Int. Sch. Res. Notices 2014, 2014. [CrossRef] [PubMed]

7. Kim, Y.K.; Son, J.S.; Kim, K.H.; Kwon, T.Y. Influence of surface energy parameters of dental self-adhesive resin cements on bond strength to dentin. J. Adhes. Sci. Technol. 2013, 27, 1778-1789. [CrossRef]

8. Petropoulou, A.; Vrochari, A.D.; Hellwig, E.; Stampf, S.; Polydorou, O. Water sorption and water solubility of self-etching and self-adhesive resin cements. J. Prosthet. Dent. 2015, 114, 674-679. [CrossRef] [PubMed]

9. Rodrigues Filho, L.E.; Burger, L.A.; Kenshima, S.; Bauer, J.R.; Medeiros, I.S.; Muench, A. Effect of light-activation methods and water storage on the flexural strength of two composite resins and a compomer. Braz. Oral Res. 2006, 20, 143-147. [CrossRef] [PubMed]

10. Antonucci, J.M.; Fowler, B.O.; Dickens, S.H.; Richards, N.D. Novel dental resins from trialkoxysilanes and dental monomers by in situ formation of oligomeric silyl ethers and silsesquioxanes. Polym. Prep. 2002, 43, 633-634.

11. Kim, Y.K.; Min, B.K.; Son, J.S.; Kim, K.H.; Kwon, T.Y. Influence of different drying methods on microtensile bond strength of self-adhesive resin cements to dentin. Acta Odontol. Scand. 2014, 72, 954-962. [CrossRef] [PubMed]

12. Van Landuyt, K.L.; Snauwaert, J.; De Munck, J.; Peumans, M.; Yoshida, Y.; Poitevin, A.; Coutinho, E.; Suzuki, K.; Lambrechts, P.; Van Meerbeek, B. Systematic review of the chemical composition of contemporary dental adhesives. Biomaterials 2007, 28, 3757-3785. [CrossRef] [PubMed]

13. Quirynen, M.; Bollen, C.M. The influence of surface roughness and surface-free energy on supra- and subgingival plaque formation in man. A review of the literature. J. Clin. Periodontol. 1995, 22, 1-14. [CrossRef] [PubMed]

14. Kim, M.J.; Kim, Y.K.; Kim, K.H.; Kwon, T.Y. Shear bond strengths of various luting cements to zirconia ceramic: Surface chemical aspects. J. Dent. 2011, 39, 795-803. [CrossRef] [PubMed]

15. Busscher, H.J.; van Pelt, A.W.J.; de Boer, P.; de Jong, H.P.; Arends, J. The effect of surface roughening of polymers on measured contact angles of liquids. Colloids Surf. 1984, 9, 319-331. [CrossRef]

16. Asmussen, E.; Peutzfeldt, A. Resin composites: Strength of the bond to dentin versus surface energy parameters. Dent. Mater. 2005, 21, 1039-1043. [CrossRef] [PubMed]

17. Van Oss, C.J.; Giese, R.F. The hydrophilicity and hydrophobicity of clay minerals. Clays Clay Miner. 1995, 43, 474-477. [CrossRef]

18. Ma, K.X.; Chung, T.S. Surface tension investigations of thermotropic liquid crystalline polymers. In Thermotropic Liquid Crystal Polymers: Thin-Film Polymerization, Characterization, Blends, and Applications, 1st ed.; Chung, T.S., Ed.; CRC Press: Lancaster, UK, 2001; pp. 157-182.

19. Bagheri, R.; Azar, M.R.; Tyas, M.J.; Burrow, M.F. The effect of aging on the fracture toughness of esthetic restorative materials. Am. J. Dent. 2010, 23, 142-146. [PubMed]

20. Da Silva, E.M.; Gonçalves, L.; Guimarães, J.G.; Poskus, L.T.; Fellows, C.E. The diffusion kinetics of a nanofilled and a midifilled resin composite immersed in distilled water, artificial saliva, and lactic acid. Clin. Oral Investig. 2011, 15, 393-401. [CrossRef] [PubMed]

21. Özcan, M.; Zamboniota, S.; Valandro, F.; Bottino, M.; Bagis, B. Microhardness of dual-polymerized resin cement around a translucent fiber post in the intraradicular environment. J. Conserv. Dent. 2011, 14, 370-373. [CrossRef] [PubMed]

22. Alshali, R.Z.; Salim, N.A.; Satterthwaite, J.D.; Silikas, N. Long-term sorption and solubility of bulk-fill and conventional resin-composites in water and artificial saliva. J. Dent. 2015, 43, 1511-1518. [CrossRef] [PubMed]

23. Bagheri, R.; Tyas, M.J.; Burrow, M.F. Subsurface degradation of resin-based composites. Dent. Mater. 2007, 23, 944-951. [CrossRef] [PubMed]

24. Geurtsen, W.; Leyhausen, G.; Garcia-Godoy, F. Effect of storage media on the fluoride release and surface microhardness of four polyacid-modified composite resins ("compomers"). Dent. Mater. 1999, 15, 196-201. [CrossRef]

25. Azar, M.R.; Bagheri, R.; Burrow, M.F. Effect of storage media and time on the fracture toughness of resin-based luting cements. Aust. Dent. J. 2012, 57, 349-354. [CrossRef] [PubMed] 
26. Silva, E.M.; Noronha-Filho, J.D.; Amaral, C.M.; Poskus, L.T.; Guimarães, J.G. Long-term degradation of resin-based cements in substances present in the oral environment: Influence of activation mode. J. Appl. Oral Sci. 2013, 21, 271-277. [PubMed]

27. Mendes, L.C.; Matos, I.C.; Miranda, M.S.; Benzi, M.R. Dual-curing, self-adhesive resin cement: Influence of the polymerization modes on the degree of conversion and microhardness. Mater. Res. 2010, 13, 171-176. [CrossRef]

28. Deb, S.; Sehmi, H. A comparative study of the properties of dental resin composites polymerized with plasma and halogen light. Dent. Mater. 2003, 19, 517-522. [CrossRef]

29. Ramos, M.B.; Pegoraro, T.A.; Pegoraro, L.F.; Carvalho, R.M. Effects of curing protocol and storage time on the micro-hardness of resin cements used to lute fiber-reinforced resin posts. J. Appl. Oral Sci. 2012, 20, 556-562. [CrossRef] [PubMed]

30. Øysæd, H.; Ruyter, I.E. Composites for use in posterior teeth: Mechanical properties tested under dry and wet conditions. J. Biomed. Mater. Res. 1986, 20, 261-271. [CrossRef] [PubMed]

31. Dentistry-Polymer-Based Filling, Restorative and Luting Materials; ISO 4049:2009; International Organization for Standardization (ISO): Geneva, Switzerland, 2009.

32. Guerra, R.M.; Duran, I.; Ortiz, P. FTIR monomer conversion analysis of UDMA-based dental resins. J. Oral Rehabil. 1996, 23, 632-637. [CrossRef] [PubMed]

33. Costanzo, P.M.; Giese, R.F.; van Oss, C.J. Determination of the acid-base characteristics of clay mineral surfaces by contact angle measurements-implications for the adsorption of organic solutes from aqueous media. J. Adhes. Sci. Technol. 1990, 4, 267-275. [CrossRef]

34. Takimoto, M.; Ishii, R.; Iino, M.; Shimizu, Y.; Tsujimoto, A.; Takamizawa, T.; Ando, S.; Miyazaki, M. Influence of temporary cement contamination on the surface free energy and dentine bond strength of self-adhesive cements. J. Dent. 2012, 40, 131-138. [CrossRef] [PubMed]

35. Good, R.J. Contact angle, wetting, and adhesion: A critical review. J. Adhes. Sci. Technol. 1992, 6, 1269-1302. [CrossRef]

36. Kim, I.H.; Park, H.S.; Kim, Y.K.; Kim, K.H.; Kwon, T.Y. Comparative short-term in vitro analysis of mutans streptococci adhesion on esthetic, nickel-titanium, and stainless-steel arch wires. Angle Orthod. 2014, 84, 680-686. [CrossRef] [PubMed] 